\title{
Asymmetrical homogamy and unequal sex ratio from reciprocal mating-order crosses between Chorthippus parallelus subspecies
}

\author{
J. L. BELLA, ${ }^{*} †$ R. K. BUTLIN, $\ddagger$ C. FERRIS \& G. M. HEWITT \\ School of Biological Sciences, University of East Anglia, Norwich NR4 7TJ, U.K.
}

\begin{abstract}
To study the evolution of this Pyrenean hybrid zone following postglacial secondary contact, a crossing programme was performed involving sequential mating of single females by males of both subspecies in both orders. Progeny were scored as embryos using Acridine orange and C-banding to identify their male parent. This revealed a number of significant departures from straightforward inheritance. There was an excess of pure over hybrid progeny. This homogamy is produced at fertilization but may have been determined before through sperm preference or competition. There was also sperm precedence with the second mating producing most of the progeny. This may be due to sperm ageing or differential storage and utilization by the female. The fundamental sex ratio in the progeny was biased towards males. Of particular interest is the finding that homogamy is markedly greater when C.p. parallelus is the mother, suggesting some form of differential biochemical recognition. This asymmetry should have important consequences for the dynamics of the hybrid zone. All these results are discussed in the light of the divergence of the two subspecies and the mixing of their genomes in the hybrid zone.
\end{abstract}

Keywords: fertilization, homogamy, hybrid zone, sperm competition.

\section{Introduction}

It is becoming apparent as more and more cases are studied that the ranges of many species are subdivided into different genotypes which can hybridize in narrow regions where they meet (Barton \& Hewitt, 1985, 1989; Hewitt 1988, 1989). Such hybrid zones are natural laboratories for the study of many facets of natural selection and speciation. Many hybrid zones occur today in regions which were inhospitable to the species in the past, and consequently have formed by secondary contact of the two forms as their ranges altered with climate changes. They are thus particularly interesting for what they reveal about the dynamics and consequences of mixing of two diverged genomes. The most obvious cases are those in Northern America and Europe which have formed after the species range expanded from more southerly refugia following the end of the last ice age some 13,000 years BP.

The consequences of such secondary contact in

*Present address: †Departamento de Biologia, CXV-Facultad de Ciencias, Universidad Autonoma, Madrid 28049, Spain and $\ddagger$ School of Pure and Applied Biology, University of Wales College of Cardiff, Cardiff CF1 3TL, U.K. terms of speciation or genetic mixing will depend on a number of features of the two diverged genomes. If the genetic divergence is such as to preclude mating or produce complete $F_{1}$ sterility then no gene flow can occur between them and they are two species. With no mating, sympatry may be possible particularly if the two genomes have distinct ecological requirements which occur in the supporting environment. With sterile $F_{1}$, sympatry will only be possible if these specific environments are distributed in large patches so that hybridization is confined to narrow strips at the edges. If, on the other hand, hybrids are fertile to some degree, then gene flow and mixing is possible; the extent of this will depend on the selection at each locus, its linkage and epistasis with other differentiating loci, and the dispersal of the organism. A variety of outcomes seems possible in principle, ranging from reinforcement of premating isolation producing full species, through stable tension zones to continuous and complete mixing of the differentiated components of the genomes. There is some debate, however, on the likelihood of these (Butlin, 1989; Harrison \& Rand, 1989; Hewitt, 1988, 1989; Ritchie \& Hewitt, 1991). Such a complex and variable process is perhaps use- 
fully approached by initially trying to understand most of the components in each of a few particular hybrid zones.

The grasshopper Chorthippus parallelus occurs across Europe and has two subspecies C.p. erythropus (Spain) and C.p. parallelus (France) which form a hybrid zone along the Pyrenees (Butlin \& Hewitt, 1985ab; Gosalvez et al. 1988; Hewitt, 1990). In these mountains the species occurs from some 300 to 2100 $\mathrm{m}$ where conditions allow. In the high cols $(1700 \mathrm{~m})$ the two subspecies would have made secondary contact at about $9000 \mathrm{BP}$ as the ice retreated. The hybrid zone is quite narrow and has been mapped for a number of characters, so that pure populations of C.p. parallelus and C.p. erythropus can be taken from the French and Spanish sides to make crosses and investigate the first stages of hybridization. There is severe testis dysfunction in $F_{1}$ males leading to complete sterility, while $F_{1}$ females are apparently just as fit as pure females (Hewitt et al., 1987a). Backcross males show intermediate testis dysfunction but produce some sperm and offspring. There is clearly an avenue for gene flow and mixing despite this considerable reduction in hybrid fitness. The songs for the two subspecies are different and there is also noticeable positive mate preferences of the pure types in a variety of laboratory experiments (Ritchie et al., 1989; R. K. Butlin \& M. G. Ritchie, in press). However, despite the presence of these two key components (namely severe hybrid unfitness and clear assortative mating) in the two pure subspecies, there is no clear evidence of reinforcement in the hybrid zone some 9000 generations of hybridization after secondary contact. Furthermore, some of the morphological, chromosomal and behavioural characters which distinguish the two subspecies show narrow clines in the cols, while others show wider clinal change through the cols, and the distance these latter characters have introgressed is rather more than predicted from field estimates of the insects dispersal (Hewitt, 1990; Virdee \& Hewitt, 1990).

Clearly the evolution of the hybrid zone after secondary contact will depend on dispersal, hybrid fitness and mating preferences, and on the precise genetics of these. It will also depend on the pattern of mating, and where there is frequent remating, on sperm competition. We know that female $C$. parallelus can mate several times, going through a receptivity cycle correlated with oviposition. Furthermore, the divergence of the two genomes before the postglacial contact may have produced differences in the ejaculates of their males, which could influence their probability or fertilization. We therefore set up a crossing programme to examine these particular aspects of the initial secondary contact.

\section{Materials and methods}

\section{Crosses}

The objective of the crossing programme was to provide females of each subspecies with either a homogametic mating followed by a heterogametic mating or vice versa. This represents four possible classes and allows for the separation of mating order effects from assortative fertilization. Either of these effects may be influenced by the interval between matings and so each group was split into three subgroups with different delays before presentation of the second male.

Grasshoppers were collected in the summer of 1985 from two localities close to the Col du Pourtalet in the western Pyrenees. C.p. parallelus were collected from the west bank of the Lac de Fabreges about $10 \mathrm{~km}$ north of the Col, and C.p. erythropus from the southern slope of the valley of the Gallego about $6 \mathrm{~km}$ south of the Col (see Butlin et al., 1991). Egg pods were collected and offspring reared in the laboratory the following summer using standard culturing techniques (Kelly-Stebbings \& Hewitt, 1972). Thirty, final, instar female nymphs of each species were isolated in individual cages and 15 were assigned to each of the four groups, denoted PEP, PPE, EPE and EEP, where the first letter represents the female, the second letter her first mate and the last letter her second mate $(\mathrm{P}=C . p$. parallelus, $\mathrm{E}=$ C.p. erythropus). Adult females were provided with moist sand for egg laying and this sand was changed daily.

Each female was allowed the opportunity to mate with a male of the appropriate subspecies from 10.00 hours to noon each day from the third day of her adult life until she mated. Copulation duration was recorded for each mating. Within each group five females were assigned to an 'immediate remating' subgroup (designated PEP0 etc.). These females were allowed the opportunity to mate on the day after their first mating and daily until they remated, thus they had the opportunity to remate without first laying an egg pod. Ten of the 20 females did so. The remainder were moved to the next subgroup which were not offered a second mating until the day after they laid their first egg pod (designated PEP1, etc.). Of the 20 females originally assigned to these subgroups, 14 remated before laying their second egg pod, three died without remating and three layed a second egg pod before remating and were moved to the final subgroup. Finally, five females from each group were allowed to lay three egg pods before being offered the opportunity to remate. Fifteen of these females survived and remated. Females were retained until they died or until they had laid five egg pods after their second mating. 


\section{Analysis of embryos}

Egg pods were stored in moist sand until some 9 days old when they were opened and the embryos dissected from the eggs and cultured for $30 \mathrm{~min}$ in 0.05 per cent colchicine in slightly hypotonic insect saline at $30^{\circ} \mathrm{C}$. They were then individually fixed in Carnoy 3:1 ethanol:acetic acid in a vial and stored at $4{ }^{\circ} \mathrm{C}$ until analysed cytogenetically.

Embryos (325) from the four different crosses were randomly chosen without knowing their pod number, egg order or the parental identification. Sixty-six of these acted as a control (see Results). Each embryo was divided into two portions. Each portion was squashed in a drop of 45 per cent acetic acid on a numbered slide. Coverslips were removed after freezing in liquid nitrogen and the slides air dried. Both sets of slides were separately processed for Acridine orange C-banding following Bella et al. (1986).

Two observers analysed each set of slides and then each slide was re-stained with Giemsa and studied again, thus each embryo was examined four times (i.e. twice per observer). The pure or hybrid character of these individuals was determined by the presence/ absence, size and position of some $\mathrm{C}$-heterochromatic markers affecting the L1, L2, L3 and M6 autosomal pairs and the $\mathrm{X}$ chromosomes (Table 1), as well as the presence of disturbed polyploid cells which characterize the hybrid individuals (Gosalvez et al., 1988; Bella et al., 1990).

Results obtained from both set of slides were counter-checked by both observers, confirming their pure or hybrid character in more than 90 per cent of the individuals. The remaining unconfirmed ones were studied again. Some individuals did not show cells in division, so we could not ascertain their pure or hybrid character. The validity of this method rests on the low number of disagreements between scores and also $a$ posteriori by the low number of individuals belonging to pods of known parentage between first and second matings that were classified incorrectly.

\section{Results}

A number of egg pods laid between the first and second mating were analysed. As these have only one possible father they provide a check on the reliability of scoring of the chromosomal markers. We were unable to score fourteen out of 66 embryos examined. Of the remainder, 37 were male of which six were scored incorrectly and 15 were female, all of which were scored correctly. The bias toward errors in male embryos was anticipated because the $\mathrm{X}$ chromosome marker is hemizygous, although the difference is not statistically significant. However, there was no bias between hybrid (3/18) and pure (3/19) males. The overall level of incorrect scoring $(11.5 \%)$ is unlikely to affect the following analysis, especially given the lack of bias between hybrid and pure embryos.

The principal questions of interest concern the proportions of hybrid and pure embryos from mothers of the two subspecies and from the different mating orders. It is immediately clear from the data summary (Table 2), however, that there is an excess of males amongst the embryos analysed. We have therefore analysed the numbers of embryos classified by four factors; subspecies of the female parent, mating order (i.e. homogametic-heterogametic versus heterogametic-homogametic), sex, and genotype (i.e. pure versus hybrid). Overall there is an excess of pure embryos over hybrid embryos $\left(65\right.$ per cent pure, $\chi^{2}=18.2$, $P<0.001)$ and an excess of males over females $(60$ per cent male, $\left.\chi^{2}=7.3, P<0.01\right)$. The excess of males was similar in embryos from females that had been mated

Table 1 Differences between C.p. parallelus and C.p. erythropus chromosomes in their response to $\mathrm{C}$-banding. These differences have been used as chromosomal markers to ascertain the pure or hybrid character of the individual embryos analysed

\begin{tabular}{lll}
\hline Chromosome & C.p. parallelus & C.p. erythropus \\
\hline $\mathrm{L}_{1}$ & Small distal band on the short arm & No distal band \\
$\mathrm{L}_{2}$ & Small distal band on the short arm & No distal band \\
& Single centromeric band may & Double centromeric band \\
& have two dots on the long arm & No dots \\
$\mathrm{L}_{3}$ & Thick distal band on the short arm & Thin band \\
$\mathrm{X}$ & Distal band & Interstitial band \\
$\mathrm{M}_{6}$ & Moderately heterochromatic & Highly heterochromatic \\
& & and multibanded \\
\hline
\end{tabular}


Table 2 Numbers of embryos found in each category. Ten male embryos were unscored for genotype and 51 were unscored for either sex or genotype. Another 66 embryos formed a control (see text)

\begin{tabular}{|c|c|c|c|}
\hline Cross & Pure & Hybrid & Total \\
\hline \multicolumn{4}{|l|}{ PEP } \\
\hline Male & 35 & 6 & 41 \\
\hline Female & 16 & 4 & 20 \\
\hline Total & 51 & 10 & 61 \\
\hline \multicolumn{4}{|l|}{ PPE } \\
\hline Male & 23 & 1 & 24 \\
\hline Female & 7 & 15 & 22 \\
\hline Total & 30 & 16 & 46 \\
\hline \multicolumn{4}{|l|}{$\mathrm{P}^{* *}$} \\
\hline Male & 58 & 7 & 65 \\
\hline Female & 23 & 19 & 42 \\
\hline Total & 81 & 26 & 107 \\
\hline \multicolumn{4}{|l|}{ EPE } \\
\hline Male & 18 & 7 & 25 \\
\hline Female & 9 & 8 & 17 \\
\hline Total & 27 & 15 & 42 \\
\hline \multicolumn{4}{|l|}{ EEP } \\
\hline Male & 18 & 10 & 28 \\
\hline Female & 3 & 18 & 21 \\
\hline Total & 21 & 28 & 49 \\
\hline \multicolumn{4}{|l|}{$\mathrm{E}^{* *}$} \\
\hline Male & 36 & 17 & 53 \\
\hline Female & 12 & 26 & 38 \\
\hline Total & 48 & 43 & 91 \\
\hline \multicolumn{4}{|l|}{ Total } \\
\hline Male & 94 & 24 & 118 \\
\hline Female & 35 & 45 & 80 \\
\hline Total & 129 & 69 & 198 \\
\hline
\end{tabular}

**T The sum of embryos of EP and PE male mating orders for $\mathrm{P}$ and $\mathrm{E}$ females, respectively.

only once ( 71 per cent males). Interactions among factors have been tested with a $G$ test (Sokal \& Rohlf, 1969).

The subspecies of the female parent influences the proportion of pure offspring $(G=11.5$, d.f. $=1$, $P<0.01)$ with a large excess of pure embryos from $C . p$. parallelus females ( 76 per cent pure) and a much smaller excess from C.p. erythropus females (53 per cent pure). Mating order influences the proportion of pure embryos $(G=8.96$, d.f. $=1, P<0.01)$. When the homogametic mating was second, 76 per cent of embryos were pure but when the heterogametic mating was second 54 per cent of embryos were pure. Female parent and mating order did not interact in their effects on the proportion of pure embryos $(G=0.04$, d.f. $=1, \mathrm{NS})$.

The sex of the offspring was not influenced by either the subspecies of the female parent $(G=0.13$, d.f. $=1$, $\mathrm{NS})$ or by the mating order $(G=1.71$, d.f. $=1, \mathrm{NS})$. However, there was a strong interaction between offspring sex and genotype $(G=26.4$, d.f. $=1$, $P<0.001)$ such that the proportion of pure offspring was much higher amongst males ( 73 per cent pure) than amongst females ( 44 per cent pure). This difference was independent of the female parent $(G=0.35$, d.f. $=1$, NS) but was greater where the homogametic mating was first $(G=7.75$, d.f. $=1, P<0.01)$.

This type of analysis cannot easily accommodate the possibility of variation among females or among egg pods, or the relationship between the proportions of different embryo types and embryo survival. These effects have been tested by using the egg pod as the unit of analysis and constructing generalized linear models with binomial error distribution and logit transformation.

This second type of analysis reveals significant variation among individual females in the proportion of pure embryos $\left(F_{31.45}=2.28, P<0.01\right)$, but both of the effects described above remain significant when tested against this variation: female parent $-F_{1.31}=5.37$, $P<0.05$, mating order $\left.-F_{1.31}=5.59, P<0.05\right)$. There was no effect of the interval between matings $\left(F_{2.31}=0.24\right)$ but the proportion of pure embryos did decline in later egg pods $(b=-0.292 \pm 0.124$ logit scale, $\left.F_{1.45}=4.15, P<0.05\right)$ independent of mating order. A similar analysis of the sex ratio revealed no significant effects.

Embryo mortality may be responsible for some of the observed effects on the proportion of pure embryos, however, while mortality did vary among individual females $\left(F_{31.189}=3.25, P<0.01\right)$, it did not vary between female subspecies $\left(F_{1.27}=1.85, \mathrm{NS}\right)$ or between mating order $\left(F_{1.27}=1.01, \mathrm{NS}\right)$. These analyses excluded the first egg pod laid which is frequently small and shows poor survival.

A further possibility is that copulation duration differs between homogametic and heterogametic matings, or between first and second matings, and influences the males' fertilization success. Second matings were longer than first matings $(t=3.31$. d.f. $=46, P<0.01)$. The difference between the duration of the first and second mating was independent of female subspecies $\left(F_{1.43}=1.69\right.$, NS $)$ but differed between mating orders $\left(F_{1.43}=6.48, P<0.05\right)$. With the homogametic mating first, the second mating was $10.81 \pm 3.44 \mathrm{~min}$ longer, while with the heterogametic mating first the second mating was only $2.08 \pm 2.30$ min longer out of a mean mating duration of $31.8 \mathrm{~min}$. 
Pure embryos were in excess in the offspring after either mating order, although much more so when the homogametic mating was second. As this is the mating combination that is shorter it suggests that any effect of copulation duration on fertilization success may be small relative to the effects of mating order.

\section{Discussion}

Differential reproductive success through sperm competition following multiple copulation has been reported and discussed by various authors in mammals (Ginsberg \& Huck, 1989; Moller \& Birkhead, 1989), birds (Birkhead et al., 1987) and insects (Parker, 1970ab; Walker, 1980; Drummond, 1984; Finke, 1984; Gwynne, 1984; see Smith, 1984 for reviews). In mammals, for example, differential fertilizing capacity seems to involve factors such as mating order, sperm longevity, sperm mobility or the ability of sperm to penetrate the eggs successfully (Ginsberg \& Huck, 1989). The advantage to mating first or last, however, varies among species, and even between studies of single species apparently depending on the timing of ovulation with respect to copulation (Foltz \& Schwagmeyer, 1989; Ginsberg \& Huck, 1989). In insects sperm are stored in the female's spermatheca between mating and oviposition, allowing for other types of interaction between ejaculates. In some species sperm from previous matings are removed during copulation; in others, sperm from different ejaculates appear to mix within the spermatheca, while in still others ejaculates are utilized on a 'last in-first out' basis (Smith, 1984). These processes have been studied extensively within populations but the additional complication of genetic divergence between mating patterns has received less attention. Conditions within the females' storage organs may discriminate against sperm from heterogametic matings or the process of recognition between sperm and egg may be disrupted. These experiments with the grasshopper Chorthippus parallelus reveal a number of significant departures from straightforward inheritance which are likely to involve a combination of these factors and which have interesting implications for the sperm competition in these insects, and for the evolutionary dynamics of this Pyrenean hybrid zone.

First and foremost is the overall excess of pure over hybrid progeny, when equality might be expected. There are two obvious possibilities to explain this: preferential fertilization by the homogametic sperm and greater mortality of hybrid embryos in the egg. Each batch of mature grasshopper eggs (10-15) is fertilized just before laying and this batch of eggs is cemented into one pod in the sand. Consequently we can compare the mortality of embryos in good pods, where none or only one egg had no embryo, with bad pods where most of the embryos were missing or dead. These two classes both show high ratios of pure:hybrid embryos (62 per cent and 75 per cent respectively) and the overall ratio of pure:hybrid embryos in the whole dataset is 65 per cent. This indicates that whilst there may be some differential hybrid embryo mortality in bad pods, the underlying ratio of pure:hybrid in good pods is the major cause of homogamy. This homogamy is produced at fertilization where fewer hybrids than pure zygotes are formed, but it may be determined either at fertilization or else before it through sperm preference or competition.

A recent series of studies in an alpine grasshopper Podisma pedestris (Hewitt et al., 1987b, 1989) also reveals homogamy between two parapatric races that differ for a sex chromosome fusion and many viability loci in the genome. Here too the evidence points strongly to preferential fertilization. In general terms these findings indicate that the genetic similarity of the homogametic sperm with the maternal genome allows this sperm, or associated assessory products, to be chemically recognized and preferred to heterogametic sperm at some stage in the female. Little is known of such mechanisms and they pose intriguing questions for investigation.

The order in which the two different males mate with the female also influences the proportion of pure embryos produced. When the homogametic mating is first only 54 per cent of embryos are pure, whilst when the homogametic mating is second some 76 per cent are pure. This suggests that there may be sperm ageing, the younger sperm from the second mating producing more progeny than when it has been stored in the female from the first mating. Whilst the experimental design allowed three different periods between first and second matings (immediate, after laying one egg pod, after laying three egg pods) there was no clear trend with the age of sperm from first mating. This lack of significance could be due to insufficient embryos being available in certain categories.

Another possibility to explain this preponderance of the second male's gametic contribution in the progeny is that of precedence, where the structure and physiology of the female sperm storage organ and reproductive tract causes the second male's sperm to be used first. In those insects that have been examined it is usual to find precedence for the sperm of the last male to mate, brought about in some cases by physical displacement (Parker, 1970a, Waage 1979, Gwynne 1984). Another suggested mechanism is that of ejaculate stacking, where the sperm bundles from the first male are stored below those of the second in the sperm- 
atheca, allowing a last-in-first-out principle to operate when sperm are transported from the spermatheca for fertilization. Only a few reports from Orthoptera exist on this topic and these show a variety of sperm predominances from first to last male (Parker \& Smith, 1975; Simmons, 1987; Backus \& Cade, 1986; Sakaluk, 1986; Hewitt et al., 1986b). All of these show sperm mixing. These present results clearly show mixing of sperm from different matings - but it is not obvious how differential utilization operates. In Drosophila melanogaster it seems that under normal conditions a female remates only when her sperm supply is depleted, conditioned by substances transferred by the male (Burnet et al., 1973; Mane et al., 1983). However, if she is confined with a male and mates again soon after, there is inefficient use of sperm and mixing (Newport \& Gromko, 1984), explained by initial storage and utilization of sperm in the ventral receptacle over sperm stored in the spermatheca. We clearly need to know more about the mechanics and physiology of sperm storage and usage in such situations.

Another somewhat unexpected result from this series of crosses is the significant sex ratio bias toward males (63 per cent). This level is also found in the embryos of females mated only once, and is thus intrinsic in these data and not just the product of double subspecific crossings. It could be due to preferential fertilization by non-X (male determining) sperm or death of XX (female) embryos. However the sex ratio bias (61 per cent males) is found in egg pods that were scored completely, i.e. all embryos alive, and also in those pods where only one egg was dead or unscored. Since eggs are fertilized after formation and go on to be laid and are not resorbed, male bias due to the death of female embryos should not occur in these complete pods. Thus it seems that preferential fertilization is the more likely explanation. This poses the question as to what is the usual sex ratio in these grasshoppers, and does it vary between crosses? If it is fundamental then is it redressed later in embryogenesis or early nymphal development? Whilst we have observed occasional departures from a 1:1 sex ratio in laboratory-reared grasshoppers, our overall impression is of equality (e.g. Ritchie et al., 1987; C. Ferris \& G. M. Hewitt, unpublished observations). This question requires deliberate experimental investigation.

Perhaps as interesting as the homogamy itself is the fact that the production of pure offspring is markedly greater when C.p. parallelus is the mother. When two types of sperm are present in a C.p. parallelus female the storage, transport or ability to fertilize of the C.p. parallelus sperm is greater than that of the C.p. erythropus sperm. But with a C.p. erythropus female, the sum of these processes leads to very little bias. It is perhaps not so surprising that homogamy has evolved by the divergence of the two genomes, so that homogametic sperm preferentially survive, move or are moved, or fertilize the egg; their chemistry is likely to be more compatible. The fact that it is more pronounced in C.p. parallelus perhaps indicates changes in the chemical compatibility during the allopatric evolution of the two genomes that are more specific to this subspecies. The evolution of asymmetry in mating systems is well known and discussed (Kaneshiro 1983, 1989) and clearly this can occur with the fertilization system as well. More particularly this asymmetry will have important consequences for the dynamics of the hybrid zone between these two parapatric subspecies.

C.p. parallelus is found along the north side of the Pyrenees while C.p. erythropus occurs on the south side. A narrow hybrid zone occurs where they make contact. Following the retreat of the ice it seems probable that C.p. parallelus met C.p. erythropus in the high cols along the Pyrenees around 9000 years BP (Hewitt, 1990). In these first mixed populations of the two subspecies, because of homogamy, C.p. parallelus females that mated with males of both subspecies would overall produce more pure offspring than C.p. erythropus females that had so mated. In the subsequent generation there would be more pure C.p. parallelus than pure C.p. erythropus individuals in the population. In addition, pure male offspring would be fertile, while hybrid males, which show severe testis dysfunction, would be sterile (Hewitt et al., 1987a). This means that the more frequent C.p. parallelus genome would tend to replace that of C.p. erythropus. A male-biased sex ratio, as found in these current experiments, would have enhanced this effect. The net outcome of this, assuming that other natural selection parameters such as viability, mating, fertility and fecundity are equal in the two subspecies, would be for the C.p. parallelus genome to advance.

The centre of the hybrid zone is now at the high point in the Col du Portalet and in other cols, where one would imagine that it first formed, however, some characters form much wider clines $(\sim 15 \mathrm{~km})$ while others are much narrower $(\sim 1 \mathrm{~km})$; also the centre of clines for some characters are not coincident with the col, being up to $3 \mathrm{~km}$ to one side or the other (R. K. Butlin et al., in press). One character, the nucleolar organizing region on the $\mathrm{X}$ chromosome, is of particular interest since it is present only in C.p. parallelus and forms a very narrow zone $4 \mathrm{~km}$ south of the col on the Spanish side (preliminary results). A similar situation has also been found recently at Col de la Quillane (preliminary results). We might expect that recombination in the generations of hybridization following postglacial contact could shuffle the genes responsible for 
the homogamy, and that homogametic effects of individual loci might be too small to detect. It is possible however, that enough of these loci are on the $\mathrm{X}$ chromosome of C.p. parallelus to promote its advance in Spain.

The mixing in the col following initial hybridization may well involve a number of factors and be complicated. However, it is open to some experimentation through the production of Bxs and further generations as a crossing programme. For example, we already know that in $F_{1}$ males where the female parent is $C . p$. parallelus there is greater meiotic disturbance than when it is C.p. erythropus (Bella et al., 1990); significantly these males differ only in the possession of the parallelus $\mathrm{X}$ chromosome with a Nucleolar Organizer Region. Such effects may be present in further generations. There are also indications of reciprocal differences in testis structure and viability in some crosses. Besides such laboratory experimentation it is clearly also important to ascertain parameters in the field, such as the frequency of remating, fecundity and the sex ratio. It will also be useful to examine different cols where mixing may have occurred for different times and under different conditions.

\section{Acknowledgements}

We wish to thank Michael Richie and Marise East for their help in crossing and fixing embryos, and Jaime Gosalvez for support and discussion. This work was funded by an MEC-British Council Fleming Fellowship to JLB, an MEC-British Council Accion Integrada, an EEC Twinning Project (SCI 0127C (JR)), a Spanish CICYT grant (PB86/0106) and NERC and SERC research grants.

\section{References}

BACKUS, V. L. AND CADE, w. H. 1986. Sperm competition in the field cricket Gryllus integer. Fla. Entomol., 69, 722-728.

BARTON, N. H. AND HEWITT, G. M. 1985. Analysis of hybrid zones. Ann. Rev. Ecol. Syst. 16, 113-148.

BARTON, N. H. AND HEWITT, G. M. 1989. Adaptation, speciation and hybrid zones. Nature, 341, 497-503.

BELLA, J. L., GARCIA DE LA VEGA, C., LOPEZ-FERNANDEZ, C. AND GOSALVEZ, J. 1986. Changes in acridine orange binding and its use in the characterisation of heterochromatic regions. Heredity, 57, 79-83.

BELla, J. L., HewitT, G. M. AND Gosalvez, J. 1990. Meiotic imbalance in laboratory produced hybrid males of Chorthippus parallelus parallelus and Chorthippus parallelus erythropus. Genet. Res., 56, 43-48.

BIRKHEAD, T. R., ATKIN, L. AND MOLLER, A. P. 1987. Copulation behaviour of birds, Behaviour, 101, 101-138.

BURNET, B., CONNOLLY, K., KEARNEY, M. AND COOK, M. 1973.
Effects of male paragonial gland secretion on sexual receptivity and courtship behaviour of female Drosophila melanogaster. J. Ind. Physiol., 19, 2421-2431.

BUTLIN, R. K. 1989. Reinforcement of premating isolation. In: Otte, D. and Endler, J. A. (eds), Speciation and its Consequences Sinauer Associates Inc., Sunderland, MA pp. 158-179.

BUTLIN, R. K. AND HEwITT, G. M. 1985a. A hybrid zone between Chorthippus parallelus parallelus and Chorthippus parallelus erythropus (Orthoptera: Acrididae): morphological and electrophoretic characters. Biol. J. Linn. Soc., 26, 269-285.

BUTLIN, R. K. AND HEWITT, G. M. 1985b. A hybrid zone between Chorthippus parallelus parallelus and Chorthippus parallelus erythropus (Orthoptera: Acrididae): morphological and electrophoretic characters. Behavioural characters. Biol. J. Linn. Soc., 26, 287-299.

BUTLIN, R. K. AND RITCHIE, M. G. 1991. Variation in female mate preference across a grasshopper hybrid zone. J. Evol. Biol. (in press).

BUTLIN, R. K., RITCHIE, M. G. AND HEWITT, G. M. 1991. Comparisons among morphological characters and between localities in the Chorthippus parallelus hybrid zone (Orthoptera: Acrididae). Phil. Trans. R. Soc. B. (in press).

DRUMMOND, B. A. 1984. Multiple mating and sperm competition in the Lepidoptera. In: Smith, R. L. (ed.) Sperm Competition and the Evolution of Animal Mating Systems. Academic Press, Orlando. pp. 291-370.

FINCKE, O. M. 1984. Sperm competition in the damselfly Enallagma hageni Waish (Odonata: Coenagrionidae): benefits of multiple mating to males and females. Behav. Ecol. Sociobiol., 14, 235-240.

FOLTZ, D. W. AND SCHWAGMEYER, P. L. 1989. Sperm competition in the thirteen-lined ground squirrel: differential fertilization success under field conditions. Am. Nat., 113, $257-265$.

GINSBERG, J. R. AND HUCK, U. W. 1989. Sperm competition in mammals. Trends Ecol. Evol., 4, 74-79.

GOSALVEZ, J., LOPEZ-FERNANDEZ, C., BELLA, J. L., BUTLIN, R. K. AND HEWITT, G. M. 1988. A hybrid zone between Chorthippus parallelus parallelus and Chorthippus parallelus erythropus (Orthoptera: Acrididae): chromosomal differentiation. Genome, 30, 656-663.

GWYNNE, D. 1984. Male mating effort. Confidence of paternity and insect sperm competition. In: Smith. R. L. (ed.) Sperm Condition and the Evolution of Animal Mating Systems. Academic Press, Orlando. pp. 117-149.

HARRISON, R. G. AND RAND, D. M. 1989. Mosaic hybrid zones and the nature of species boundaries. In: Otte, D. and Endler, J. A. (eds) Speciation and its Consequences. Sinauer Associates Inc., Sunderland, MA, pp. 111-133.

HEWITT, G. M. 1988. Hybrid zones - natural laboratories for evolutionary studies. Trends Ecol. Evol., 3, 158-167.

HEWITT, G. M. 1989. The subdivision of species by hybrid zones. In: Otte, D. and Endler, J. A. (eds) Speciation and its Consequences. Sinauer Associates Inc., Sunderland, MA pp. 85-110.

HEWITT, G. M. 1990. Divergence and speciation as viewed from an insect hybrid zone. Can. J. Zool., 68, 1701-1715. 
HEWITT, G. M., BUTLIN, R. K. AND EAST, T. M. 1987a. Testicular dysfunction in hybrids between parapatric subspecies of the grasshopper Chorthippus parallelus. Biol. J. Linn. Soc., 31, 25-34.

HEWITT, G. M., NICHOLS, R. A. AND BARTON, N. H. 1987b. Homogamy in a hybrid zone in the alpine grasshopper Podisma pedestris. Heredity. 59, 457-466.

HEWITT, G. M., MASON, P. AND NICHOLS, R. A. 1989. Sperm precedence and homogamy across a hybrid zone in the alpine grasshopper Podisma pedestris. Heredity, 62, 343-353.

KANESHIRO, K. Y. 1983. Sexual selection and the direction of evolution in the biosystematics of Hawaiian Drosophilidoc. Ann. Rev. Entomol., 28, 161-178.

KANESHIRO, K. Y. 1989. The dynamics of sexual selection and founder effects in species formation. In: Giddings, L. V., Kaneshiro, K. Y. and Anderson, W. W. (eds)., Genetics, Speciation and the Founder Principle. Oxford University Press, Oxford. pp. 279-296.

KELLY-STEBBINGS, A. F. AND HEWITT, G. M. 1972. The laboratory breeding of British Gomphocerine grasshoppers (Orthoptera: Acrididae). Acrida, 1, 233-245.

MANE, S. D., TOMPKINS, L. AND RICHARD, R. C. 1983. Male esterase 6 catalyses the synthesis of a sex pheromone in Drosophila melanogaster females. Science, 22 2, 419-421.

MOLLER, A. P. AND BIRKHEAD, T. R. 1989. Copulation behaviour in mammals: evidence that sperm competition is widespread. Biol. J. Linn. Soc., 38, 119-131.

NEWPORT, M. E. A. AND GROMKO, M. H. 1984. The effect of experimental design on female receptivity to remating and its impact on reproductive success in Drosophila melanogaster. Evolution, 38, 1261-1272.

PARKER, G. A. 1970a. Sperm competition and its evolutionary consequences in the insects. Biol. Rev. Camb. Philos. Soc., 45, 525-567.

PARKER, G. A. 1970 b. Sperm competition and its evolutionary effect on copula duration in the fly Scatophaga stercolaria. J. Insect Physiol., 16, 1301-1328.

PARKER, G. A. AND SMITH, J. L. 1975. Sperm competition and the evolution of the precopulatory passive phase behaviour in locusta migratoria migratoriodes. J. Ent., 49, 155-171.

RITCHIE, M. G. AND HEWITT, G. M. 1991. Outcomes of negative heterosis. In: Masters, J. and Spencer, H. (eds) Mate Recognition and Speciation Cambridge University Press, Cambridge (in press).

RITCHIE, M. G., BUTLIN, R. K. AND HEWITT, G. M. 1987. Causation, fitness effects and morphology of macropterism in Chorthippus parallelus (Orthoptera: Acrididae). Ecol. Entomal., 12, 209-218.

RITCHIE, M. G., BUTLIN, R. K. AND HEWITT, G. M. 1989. Assortative mating across a hybrid zone in Chorthippus parallelus (Orthoptera: Acrididae). J. Evol. Biol., 2, 339-352.

SAKALUK, S. K. 1986. Sperm competition and the evolution of nuptual feeding behaviour in the cricket Gryllodes supplicans (Walker). Evolution, 40, 584-593.

SIMMONS, L. w. 1987. Sperm competition as a mechanism of female choice in the field cricket, Gryllus bimaculatus. Behav. Ecol, Sociobiol., 21, 197-202.

SMITH, R. L. (ed.). 1984. Sperm Competition and the Evolution of Animal Mating Systems, Academic Press, London, 687 pp.

SOKAL, R. R. AND ROHLF, F. J. 1969. Biometry, W. H. Freeman \& Co., San Francisco.

VIRDEE, S. R. AND HEWITT, G. M. 1990. Ecological components of a hybrid zone in the grasshopper Chorthippus parallelus (Zetterstedt) (Orthoptera: Acrididae). Bol. San. Veg. Plagas, 20, 299-309.

WAAGE, J. K. 1979. Dual function of the damsel fly penis: Sperm removal and transfer. Science, 203, 916-918.

WALKER, W. F. 1980. Sperm utilization strategies in non-social insects. Am. Nat., 115, 780-799. 